\title{
DESARROLLO DE LA PERSONA EN LA ORGANIZACIÓN: UN COMPROMISO INDIVIDUAL
}

\author{
IgNACIO ÁLVAREz DE MON \\ Profesor de Comportamiento Organizacional y Subdirector del Centro de liderazgo \\ DEL INSTITUTO DE EMPRESA DE MADRID
}

\section{Resumen}

En este artículo se cuestiona hasta qué punto la abundante literatura existente sobre temas relacionados con el desarrollo' de las personas en las organizaciones empresariales se compadece con la realidad vivida en las empresas actualmente, proponiéndose una visión alternativa. Bebiendo en fuentes más clásicas y multidisciplinares, se plantea la necesidad de un fundamento filosófico, individual y profundamente humanista que permita una práctica personal y organizativa más coherente con la esencia del desarrollo. Desde esta base filosófica, pueden cobrar más sentido algunas políticas empresariales verdaderamente orientadas a potenciar el desarrollo de las personas en las organizaciones.

Palabras clave

Desarrollo personal, organizaciones empresariales, filosofía de empresa, humanismo, compromiso individual.

\section{Abstract}

This article questions how close is the increasing current literature about personal development in business organizations to the present and real situation lived by people working in those organizations. From that perspective, an alternative vision is showed consisting in a philosophical base, with important components of individualism and humanism, that allows personal and organizational practices be more in accordance with an authentic personal development approach. From this new philosophy, it will probably be easier to make sense out of some firms' policies truly oriented to develop its employees.

\section{Key Words}

Personal development, business organizations, business philosophy, humanism, individual compromise.

\footnotetext{
En adelante, se entenderá por desarrollo la adquisición y/o perfeccionamiento de determinadas capacidades y competencias de tipo personal y/o profesional.
} 


\section{INTRODUCCIÓN}

En un reciente estudio sobre "Las características del éxito del liderazgo"2, realizado con 276 grandes empresas de todo el mundo, se seleccionaron 34 factores, entre un total de 195, como los más relevantes a la hora de identificar lo que se denomina empresas de "liderazgo de primera calidad". De estos 34 factores, a su vez, 6 de los 8 con una mayor influencia hacen referencia al desarrollo de la persona en la organización:

1. Los ejecutivos de alta dirección son buenos modelos que seguir para el desarrollo de sus empleados.

2. Los ejecutivos creen que el desarrollo es importante.

3. La empresa modifica sus planes de desarrollo en función de la estrategia empresarial.

4. Los jefes de línea hacen del desarrollo un tema prioritario.

5. La empresa reconoce públicamente a los directivos que desarrollan a sus empleados.

6. Los directivos son evaluados en sus revisiones del rendimiento por el desarrollo de sus empleados.

En otro estudio realizado sobre "La concepción española del liderazgo"3, en el que participaron 76 presidentes, consejeros delegados y directores generales de las principales empresas españolas, se recogieron las preferencias de estos dirigentes clasificándolas por determinados estilos de dirección, así como sus creencias y filosofía de gestión respecto a las motivaciones de los subordinados.

Entendiendo el liderazgo como la capacidad de influencia en los demás, los estilos de liderazgo representan patrones conductuales de influencia de cierta permanencia en el tiempo y que definen la relación entre un líder y sus seguidores. Estos son los 5 estilos de liderazgo considerados en el estudio y las principales características que los definen:

1. Estilo directivo - coercitivo: los subordinados actúan de acuerdo con las normas del líder para eludir posibles castigos que se les pueden aplicar. Los líderes coercitivos suelen limitar el campo de actuación de los subordinados, controlan la información y establecen pautas específicas de actuación, esperando que los demás se adapten a su planificación y coordinación del trabajo.

2. Estilo transaccional: el líder transaccional define la relación con los subordinados en términos de intercambio. Para que este estilo sea efectivo, el líder debe tener acceso a recursos valorados por los seguidores. A largo plazo, sin embargo, necesitará refuerzos continuos para mantener la motivación de los subordinados.

\footnotetext{
2 "Las características del éxito del liderazgo", estudio de investigación del Corporate Leadership Council, Washington, 2003.

"La concepción española del liderazgo", estudio de investigación conjunto del Centro de Liderazgo del Instituto de Empresa y Deloitte, Madrid, 2004
} 
3. Estilo participativo: el liderazgo participativo permite a los subordinados influir en las decisiones del líder, a través de consultas, toma de decisiones conjuntas, mecanismos para compartir el poder o procedimientos tendentes a la descentralización y democratización de los órganos de gobierno de la organización. Los empleados se sienten partícipes en todas aquellas cuestiones que afectan directa o indirectamente al desempeño de su labor profesional.

4. Estilo visionario: se fundamenta en el carisma y cualidades personales del líder para suscitar aspiraciones nuevas y obtener el compromiso de sus seguidores. El líder visionario actúa como modelo de conducta para sus subordinados y establece relaciones de tipo emocional con ellos. Los colaboradores se identifican con el líder y manifiestan una motivación y entrega extraordinarias. El líder transmite una visión de futuro diferente y atractiva para los subordinados.

5. Estilo desarrollador: el líder contribuye a que mejoren las capacidades y aptitudes de sus seguidores, teniendo una consideración individual hacia cada uno de ellos y actuando como un permanente estímulo intelectual. El líder potencia las características individuales y ofrece continuos retos que propician el desarrollo personal de los liderados. Inspira en sus seguidores la asunción de responsabilidades y compromisos individuales y propicia una dirección por objetivos personales.

En relación con estos 5 estilos de liderazgo, el estudio arroja los siguientes resultados:

- Directivo - coercitivo: sólo el $14 \%$ de los encuestados reconocen utilizar este estilo normalmente o casi siempre.

- Transaccional: $67 \%$.

- Participativo: $63 \%$.

- Visionario: $80 \%$.

- Desarrollador: $85 \%$.

El mismo estudio recoge, además, las creencias de estos dirigentes sobre la dirección de personas basándose en la Teoría X e Y de McGregor (McGregor, 1985). Según esta teoría, la filosofía de gestión de los directivos determina su práctica posterior. Los comportamientos y actitudes de los líderes hacia sus subordinados se basan en presunciones asumidas por estos directivos respecto a las personas en general, a los empleados de una compañía en particular y a la función directiva como tal. Estas presunciones fundamentan una filosofía de la dirección de personas que influye, en última instancia, en el nivel de satisfacción y productividad de los empleados y, por consiguiente, de su desarrollo como personas en la organización.

El modelo se basa en reflejar dos premisas opuestas sobre la condición de la naturaleza humana. La primera, llamada Teoría X, se fundamenta en la creencia de que la gente se muestra básicamente reacia a trabajar en favor de los intereses de la empresa, no es capaz de asumir responsabilidades y debe ser estrechamente supervisada, presionada e incluso sancionada para que 
realice convenientemente su trabajo. Por el contrario, la Teoría Y se basa en la creencia de que los empleados están intrínsecamente predispuestos a aceptar responsabilidades, a hacer las cosas lo mejor posible y a trabajar en favor de los intereses de la empresa. Desde esta perspectiva, es responsabilidad de la dirección la creación y mantenimiento de las condiciones laborales que permitan a los empleados materializar sus posibilidades de desarrollo al máximo.

En este apartado, los resultados del estudio son los siguientes:

- Un 46\% de los encuestados se muestra predominantemente de acuerdo con los postulados de la Teoría Y.

- Un $26 \%$ se muestra predominantemente de acuerdo con los postulados de la Teoría X.

- El $28 \%$ restante está en una zona intermedia entre una y otra.

Los datos recabados en ambos estudios invitan a múltiples y diferentes interpretaciones. Desde una perspectiva optimista, éstas podrían ser algunas de ellas:

- Tal vez, exista un mayor grado de concienciación entre nuestros dirigentes empresariales respecto a la necesidad de cuidar a las personas, su talento y su motivación, contribuyendo con ello a su desarrollo personal y profesional.

- Es posible que estos dirigentes se hayan convencido de que esta es la mejor manera de asegurar un rendimiento laboral alto y sostenido en el tiempo.

- El contexto actual, además, favorece este planteamiento: globalización, diversidad, multiculturalidad, estructuras empresariales más horizontales, con menos niveles jerárquicos, mercados laborales más dinámicos, tendencias demográficas que contribuyen a la escasez de talento, una economía del conocimiento y de la información que hace del talento un recurso valioso además de escaso, etc.

Sin embargo, también parece lícito cuestionarse la autenticidad de estos planteamientos, sobre todo desde la perspectiva de más de un profesional harto de grandes discursos vacíos de contenido real. Cuando hablamos de organizaciones empresariales, el contenido real de los discursos se debe reflejar en políticas y prácticas aplicadas en el día a día a sus profesionales y en relación con los temas que de verdad les importan: selección, formación, evaluación del rendimiento, retribución, carrera profesional, retención,...

No es raro contemplar, todos tenemos ejemplos, cómo una organización o, lo que es lo mismo, sus máximos dirigentes, contradicen su discurso teórico con su práctica cotidiana:

- "Apostamos por desarrollar el talento de nuestra gente".

Para ello, creamos lo que se llama una "bolsa de talento", es decir, una forma de seleccionar y dividir a aquellos que pueden aspirar a más de los que no, los listos de los tontos, los que pueden dar más de sí y los que ya han alcanzado su techo. 
- "En esta organización valoramos y reconocemos a aquellas personas que contribuyen al desarrollo de otras".

¿Qué influencia práctica y real tiene en el desarrollo profesional de un empleado su contribución al desarrollo profesional de otros? ¿ Qué implicaciones tiene en su nivel retributivo a corto, medio y largo plazo? ¿Qué otras compensaciones obtiene un directivo que desarrolla a su gente respecto al que no lo hace? ¿̇ Hasta qué punto los resultados puros y duros de negocio no son lo único que se valora?

- "Aquí premiamos la iniciativa, la creatividad y el compromiso con la institución".

¿Qué pasa realmente con aquéllos que tienen iniciativas, que se salen de la norma, que, de vez en cuando, buscan formas alternativas de hacer las cosas? ¿Cuántas veces sus iniciativas no obtienen como respuesta el típico "así son las cosas aquí", "así se han hecho siempre" o "estas son las normas"? ¿Quiénes gobiernan en las organizaciones: los que tienen iniciativas y las llevan a la práctica con éxito o los burócratas encargados de limitar estas iniciativas y encorsetarlas en rígidos procedimientos que acaban por ahogarlas?

- "Nuestros empleados son el mejor activo con el que cuenta nuestra empresa".

Eso sí, cuando llega el momento de designar a alguien para un puesto clave, se tira de talonario y se trae a "la estrella" de fuera, ya que los de dentro siempre adolecen de algo: falta de experiencia, excesivo conformismo, ausencia de liderazgo, ...

La realidad no suele ser blanca o negra, siempre hay matices, pros y contras, aspectos que ponderar y que criticar. Además, cada organización es diferente y cada persona es un mundo. Pero, en cualquier caso, lo que sí parece claro es que detrás de las estrategias y tácticas, más allá de las políticas y procedimientos e, incluso, por encima de las tan manoseadas "herramientas de gestión" de las que tan ávidos están los profesionales dedicados a estos temas, debe de haber algo más. Ese algo más es el fundamento de todo lo que estamos hablando y si esa base no existe todo lo demás acaba resultando endeble, incoherente y artificial.

Al hablar de personas, de las que dirigen y lideran y de las que son dirigidas y lideradas, sus comportamientos, actitudes, motivaciones, capacidades de mejora y desarrollo, ese fundamento ha de ser filosófico. Me refiero a unos determinados principios, puntos de partida y de llegada, sin los cuales es difícil encontrar el sentido último de lo que hacemos. Cuando hablamos de desarrollo hablamos de algo verdaderamente importante para las personas, elevamos las expectativas de la gente, les transmitimos aspiraciones nuevas y les planteamos nuevos desafíos. ¿ Cuál es el fondo de todo esto? ¿̇Es sólo una "herramienta" más al uso para "motivar"? Me temo que determinados asuntos conviene tenerlos pensados, reflexionados, profundamente asumidos y bien planteados antes de participárselos a los demás. De lo contrario, actúan como "caja de Pandora" o "boomerang", desatando toda su furia contra aquél que los promovió y arrastrando a mucha gente de buena voluntad en el camino.

Reflexionemos sobre cuáles pueden ser esos principios que sirven de base al desarrollo personal y que rigen para todas las personas, líderes y liderados, en todas las épocas, lugares y mo- 
mentos y que se pueden aplicar en cualquier tipo de organización, empresarial o no. Mientras lo hacemos, pensemos en nuestra propia trayectoria profesional y personal y comprobemos hasta qué punto esos principios realmente son de aplicación universal. En palabras de Jim Collins: "El mundo cambia y continuará haciéndolo. Pero eso no significa que debamos detenernos en la búsqueda de principios intemporales. ... Me gusta pensar que nuestro trabajo consiste en la búsqueda de esos principios intemporales aplicados a la organización, que seguirán vigentes con independencia de los cambios que experimente el entorno en cada momento. La aplicación específica de estos principios cambiará, pero ciertas leyes inmutables de comportamiento humano en las organizaciones permanecerán" (Collins, 2001: 15).

Pasemos a reflejar estos principios, sin ánimo de exclusión, novedad, trascendencia, importancia o abstracción, sino con la sana intención de proponer un cauce de reflexión no tan común entre personas (empresarios, directivos, profesionales en general) acostumbradas a otro tipo de argumentaciones, quizás más concretas y operativas, más "pegadas a su día a día". Puede que ese tipo de argumentaciones adolezcan de una base teórica de partida más sólida que haría las actuaciones posteriores más coherentes con su supuesto fin. Teoricemos y filosofemos un poco, sobre todo en la medida en que comprobemos que no hay nada más práctico que una buena filosofía.

\section{CONFIANZA EN EL DESARROLLO POTENCIAL DE LA NATURALEZA HUMANA}

Lo primero que debe tener una persona que aspira a propiciar el desarrollo de las demás, partiendo, entre otras cosas, de su propio desarrollo, es una clara conciencia del valor del individuo en sí mismo, por su mera condición humana. Se trata de la creencia básica en que todo hombre debe reclamar para sí la dignidad que le es consustancial.

Tomar conciencia de uno mismo resulta tan fundamental como el propio desarrollo y toda persona tiene el deber y el derecho de hacerlo. Sin embargo, paradójicamente, con frecuencia lo más evidente nos resulta lo más difícil de identificar. No es raro contemplar la trayectoria errada de más de un profesional que se ha transformado en víctima de su propia indiferencia y destructividad. Curiosamente, "... la situación paradójica, y trágica, del hombre es que su conciencia es tanto más débil cuanto más la necesita" (Fromm, 1957: 175).

A menudo, no sabemos lo que queremos realmente porque no nos lo hemos planteado seriamente ni siquiera una vez. Objetivos operativos, cifras de negocio, partidas presupuestarias, se asumen como metas incuestionadas a las cuales sometemos automáticamente voluntades, esfuerzos y dedicaciones. "Empleamos toda nuestra energía con el fin de lograr nuestros deseos, y en su mayoría las personas nunca discuten las premisas de tal actividad; jamás se preguntan si saben realmente cuáles son sus verdaderos deseos. No se detienen a pensar si los fines perseguidos representan algo que ellos, ellos mismos, desean" (Fromm, 1995: 241).

Otro error en el que caemos reiteradamente consiste en buscar a alguien diferente del que somos, tratar de inventarnos de nuevo, cuando lo que en realidad deberíamos hacer es redescu- 
brirnos, tal y como somos. Deberíamos buscar, descubrir y aprender quiénes somos y, de este modo, acabar asumiendo razonablemente lo que no podemos cambiar. Cambiar no es lo mismo que convertirse en otro (O'Toole, 1999).

Consustancial al desarrollo es el llegar a ser que, por definición, es un no ser todavía, una posibilidad de ser. Existe más como probabilidad que como realidad. La actividad profesional representa una importante faceta en la que explotar ese potencial y convertirse en lo que uno puede y debe llegar a ser. En este contexto, lo bueno y lo malo se identifican con la mayor o menor aproximación a ese ser potencial: "La virtud es la responsabilidad hacia la propia existencia. Lo malo lo constituye la mutilación de las potencias del hombre. El vicio es la irresponsabilidad hacia sí mismo" (Fromm, 1957: 32).

\section{EXPLORAR ES MÁS IMPORTANTE QUE LLEGAR}

A menudo, la gente confunde el desarrollo personal con la carrera profesional. Está claro que son dos realidades complementarias, pero no iguales. El desarrollo personal y profesional de un individuo deberá tener un reflejo en su trayectoria profesional, en una determinada organización o fuera de ella. Con frecuencia, las organizaciones empresariales caen en dos posturas extremas respecto al diseño de las carreras de sus empleados. Algunas planifican exhaustivamente los más importantes hitos en la trayectoria profesional de sus trabajadores, anticipando en detalle futuros puestos, funciones, responsabilidades y, sobre todo, compensaciones. Otras, improvisan el discurrir profesional de sus colaboradores, asignándoles cometidos diversos en función, exclusivamente, de las necesidades concretas que en ese momento tiene la organización. Intentar planificar de hoy en adelante, para el resto de nuestros días, cuál va a ser la carrera profesional de alguien, puede ser tan excesivo y frustrante como pretender que un joven de 14 años sepa ya quién será su pareja, cuántos hijos tendrán, cómo les llamarán y dónde vivirán el resto de sus vidas. El territorio suele ser más rico, diverso y complejo que el mapa que tenemos de él. No se trata de improvisar o despreciar la planificación, sino de entender que una carrera profesional debe contribuir al desarrollo que la persona demanda en cada momento, aportando además valor a la organización que le paga. Una planificación excesiva puede resultar tan frustrante y limitadora como su total ausencia.

Es mucha la obsesión hoy en día por establecer planes de carrera, itinerarios profesionales, como si de una línea de metro se tratara, con las estaciones ya dispuestas y el tiempo estimado que vamos a estar en cada una de ellas. Además, como en las líneas de metro en hora punta, suele haber aglomeración, atascos y la ambición de todos por llegar a la salida antes que los demás. ¿̨ué pasa si nos detenemos en una estación, que no era la prevista, nos sentamos en un banco, mientras todo el mundo corre, y nos planteamos si a lo mejor nuestra línea era otra? No te digo ya si nos planteamos ir andando o en autobús, para variar. No se nos permite dudar. La aspiración generalmente extendida es la de tener una carrera vertical, ascendente y rectilínea, tan rápida como sea posible. Ese es el síntoma más claro de una persona exitosa. "En vez de a creer, actitud que viene ya impuesta por la cultura tradicional, habría que enseñar a dudar; a distinguir y apreciar la calidad de lo creíble. El hombre es más humano cuando duda, que cuando robotiza sus actos impulsado por sus creencias"(Olmos, 1994: 80). 
Las personas, en búsqueda de su desarrollo profesional, se encuentran en ocasiones siguiendo caminos que no son los suyos, caminos que han ido recorriendo en un permanente afán por reafirmar una trayectoria iniciada. Pero este discurrir acaba pasando factura, el esquema se ve cuestionado por alguna persona que lo descabala o por algún acontecimiento nuevo no controlado. "Así, lo que en realidad nos trastorna no son esas personas o esos sucesos, sino el modelo que llevamos dentro. El tal modelo, para colmo, es accidental y arbitrario. Cae en la cuenta de eso y nada volverá a trastornarte" (Vallés, 1987: 63).

\section{PENSAR EN LIBERTAD, ACTUAR CON RESPONSABILIDAD}

Desarrollarse significa crecer, madurar, y para eso hay que decidir, optar y hasta errar. Pobre de la organización que intente impedir a toda costa que la gente se equivoque, acabará haciendo suyos los fracasos de esa gente. No podemos tomar por los demás decisiones que les son propias, tampoco podemos limitar el desarrollo de las personas a un esquema rígido que no admita alternativas.

El ser humano está constantemente sometido a la presión de tener que tomar decisiones. El hombre, como dice Sartre (1960), está condenado a ser libre, condenado a elegir, a regir sus actos, vivirá para hacer o dejar de hacer algo, y eso ya será una opción. Según este autor, cada situación es nueva y cada elección es la creación de una nueva situación. Aceptar esta responsabilidad por nuestras elecciones, con toda la angustia e incertidumbre que supone, es vivir auténticamente, de acuerdo con la propia condición de la naturaleza humana. El riesgo y la incertidumbre son inherentes a la propia decisión: "...el mal consiste únicamente en preferir las cosas inferiores a las superiores, en poner las cosas superiores al servicio de las inferiores." (Lavelle, 1951: 691).

La asunción responsable de la propia libertad, es decir, de la capacidad de tomar decisiones por nosotros mismos, es signo de madurez tanto por parte de la organización que la admite como del individuo que la acepta. Hay que evitar que las personas se sientan prisioneras de las organizaciones en las que trabajan. Si las personas no crecen, las organizaciones en las que están tampoco y ambos acaban siendo rehenes el uno del otro. Todo el mundo debería buscar el desarrollo "para" más que el desarrollo "en" una organización. Mi desarrollo es el que es, el que yo me marco, y la organización en la que hoy estoy me ayuda en ese desarrollo. A cambio, yo contribuyo con mi trabajo y dedicación. Si este acuerdo tácito o explícito puede durar toda la vida, bienvenido sea, y si no, asumamos que fue bueno mientras duró.

No parece que los tiempos que corren permitan todavía excesivas muestras de paternalismo por parte de las empresas, o de minoría de edad por parte de los empleados. "La coacción ha de venir de dentro [...] pues la coacción autoimpuesta es signo de madurez. Mientras la persona dependa totalmente de normas externas sigue siendo menor de edad. [...] Lo difícil es ser autónomo. Lo fácil es pedir leyes y echarle la culpa a la mala legislación de las deficiencias del comportamiento colectivo" (Camps, 1996: 67). Esta llamada a la responsabilidad le vendría bien a más de 
un profesional cuyo margen de actuación dentro de la organización en la que trabaja suele ser mayor de lo que él mismo se reconoce.

Es fácil encontrar excusas para no hacer lo que debemos, siempre están al alcance de la mano unas cuantas: jefe, central, burocracia, organización, políticas, lo que hacen los demás o lo que creemos que hacen, lo que siempre se ha hecho hasta ahora, etc. "Por ser libre, y cualquiera que sean los condicionamientos causales a que esté sometido, de mí y solo de mí procede la última y definitiva decisión. Por muy fuertemente que el carácter, el temperamento, la herencia genética, el clima, la alimentación, el ejemplo, la educación, etc., me empujen [...] Si esos condicionamientos procedentes del reino de lo natural se impusieran a mi libertad, ya no sería un ser humano, sino un ente más de la naturaleza" (Méndez, 1988: 234).

"El líder, ¿̇nace o se hace?"; qué típica la pregunta y, a veces, qué típica la respuesta: "Uno puede esforzarse pero, a fin de cuentas, o se nace con ello o no hay nada que hacer". Más de una vez me he encontrado esa respuesta de algún asistente, se supone que voluntario, a un curso de liderazgo. Paradójicamente, se asiste a un curso para formarse en algo que se considera innato, es decir, no adquirible por medio del esfuerzo, la experiencia, la práctica y la dedicación. ¿Qué hay detrás de estos planteamientos?, ¿por qué tanta necesidad insatisfecha de líderes carismáticos? Supongo que las posibles razones son muchas y variadas pero, al hilo de lo que estamos tratando, creo que detrás de estos planteamientos hay un pánico horrible, mezclado con desidia tediosa, a asumir la propia responsabilidad.

El sentido profundo de la libertad va intrínsecamente unido al concepto de responsabilidad. Ambos forman parte de lo que podríamos denominar compromiso personal, es decir, la tendencia a ser y hacer en nuestras vidas aquello que queremos y debemos. Las organizaciones deberían promover que las personas busquen su propio encaje y que, fruto de ese encaje, sean capaces de aportar más. "Responsabilidad es saber que cada uno de mis actos me va construyendo, me va definiendo, me va inventando. Al elegir lo que quiero hacer voy transformándome poco a poco. Todas mis decisiones dejan huella en mí mismo antes de dejarla en el mundo que me rodea" (Savater, 1991: 117).

Nadie, sino uno mismo, tiene la suprema responsabilidad de contribuir a su pleno desarrollo como persona. Lo que nos puedan aportar los demás, o lo que podamos nosotros aportarles a ellos, bienvenido sea, pero la iniciativa debe provenir de uno mismo. Ortega afirmaba la necesidad de todo hombre de imperar sobre sí mismo si pretendía dirigir a los demás (Ortega, 1947). La verdadera naturaleza de un líder se forja en su capacidad de dirigirse a sí mismo. Santiago Álvarez de Mon habla de un dominio de la propia personalidad libre, responsable y maduro del que todo ser humano es capaz, por difícil que parezca. "A los políticos, directivos, profesores, profesionales que contribuyen a que surja, cuaje y se consolide, no tendré ningún empacho en llamarles líderes. A los que lo obstaculizan mediante la anestesia intelectual, la manipulación mediática y la bajeza moral, les intentaré redefinir en términos menos elogiosos" (Álvarez de Mon, 2000: 29).

El mismo autor comenta que el desarrollo personal debe ser el primer reto de todo individuo que aspire a liderar. En este empeño, debemos ser autosuficientes, nos lo debemos y no podemos 
esperar que nadie más pague esa deuda por nosotros. "Este es el verdadero leit motiv de todo el libro, animar a cada persona a ser ella misma, quienquiera que sea, en lugar de esperar la llegada del líder mágico que en el mejor de los casos me dormirá y acunará" (Alvarez de Mon, 2000: 184).

A ninguna organización, por buena que sea y por más que nos identifiquemos con ella, le debemos cargar con la responsabilidad de nuestro desarrollo profesional. La carga es tan excesiva en un lado, el de la organización, como lo es la descarga en el otro, el de la responsabilidad individual. "He confiado a otros una participación en los asuntos supremos de la Humanidad, una seriedad y una exactitud que en ningún modo había encontrado en mí mismo. Los he apreciado infinitamente más que a mí. ¿̇De dónde pueden haber adquirido su conocimiento de lo verdadero sino de la propia reflexión? Y, puesto que soy lo mismo que ellos, ¿̇por qué no puedo encontrar la misma verdad mediante idéntica reflexión? ¡Cuánto me he menospreciado!" (Fichte, 1963: 22).

El viaje del desarrollo es bonito, atractivo, interesante, puede que hasta espectacular. Pero también puede ser un viaje de incertidumbres, contrastes, sinsabores e incomodidades. El buen viajero incorpora lo segundo en lo primero, interpretándolo más como aliciente que como decepción. Asume resignadamente lo que no puede cambiar, disfruta cada uno de los buenos momentos y se centra en actuar sobre lo que está a tiempo de mejorar.

$\dot{¿}$ Somos verdaderamente libres de elegir nuestro propio desarrollo? $\dot{¿}^{N}$ o nos traería ese pensamiento más problemas que soluciones? Pocos pensadores han reflejado tan profunda e intensamente como Viktor Frankl la maravilla y el drama que supone la libertad del hombre. Él mismo vivió este terrible dilema al afrontar un penoso cautiverio en un campo de concentración nazi. Marcado, probablemente, por esta dramática experiencia, Frankl dedicó buena parte de sus esfuerzos posteriores a intentar encontrar un sentido a la vida y, sobre todo, un sentido a la libertad

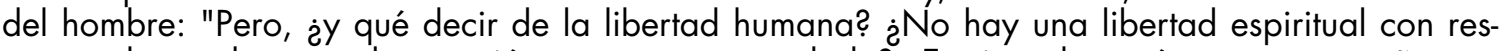
pecto a la conducta y a la reacción ante un entorno dado? ¿ ¿Es cierta la teoría que nos enseña que el hombre no es más que el producto de muchos factores ambientales condicionantes, sean de naturaleza biológica, psicológica o sociológica? ¿̇El hombre es sólo un producto accidental de dichos factores?" (Frankl, 1979: 68).

Estas mismas preguntas nos las hacemos muchos de nosotros a diario con menos motivo que Víctor Frankl o, dicho de otra forma, ante situaciones no tan extremas como la que él vivió. Sin embargo, su respuesta es decidida en defensa de la capacidad última de elección del hombre, incluso ante las circunstancias físicas y psíquicas más terribles que le puedan tocar vivir : "[...] al hombre se le puede arrebatar todo salvo una cosa: la última de las libertades humanas, la elección de la actitud personal ante un conjunto de circunstancias, para decidir su propio camino" (Frankl, 1979: 69).

La fe en el hombre, en sus posibilidades y naturaleza perfectible, consolida los cimientos sobre los que construir toda esta teoría: "¿Qué es en realidad el hombre? Es el ser que siempre decide lo que es. Es el ser que ha inventado las cámaras de gas, pero asimismo es el ser que ha entrado en ellas con paso firme musitando una oración" (Frankl, 1979: 87). 


\section{UN POCO MÁS DE OSADÍA, UN POCO MÁS DE CORAJE}

Algunas dinámicas organizativas no ayudan, precisamente, a que las personas se singularicen. No es raro contemplar cómo las rígidas estructuras y las incuestionables estrategias nos hacen derivar hacia cometidos y desempeños muy alejados de nuestro ideal. Es precisamente eso, el ideal, lo que aprendemos a sacrificar en favor de una organización que, finalmente, ni siquiera lo reconoce. Tanto esfuerzo, sacrificio y renuncia, ¿̇para qué? Y culpamos a todos y a todo de lo que nos pasa, de lo que nos ha pasado. Y nos consolamos, estúpidamente, de que el mal que nos afecta le afecta a la mayor parte de la gente que conocemos, y a los que no, es que mienten o viven en otro planeta. ¿2Rebelarnos? ¿ ¿para qué? ¿̇contra qué o quién?, ¿̇por qué?

Estamos entre el miedo y la resignación, mezclados con la desidia, la amargura, el escepticismo y el mal humor. ¿Causas? Hay una muy probable y, sin duda, de las más importantes: la renuncia a ser uno mismo, a la propia libertad. "[...] en nuestro esfuerzo por escapar de la soledad y la impotencia, nos disponemos a despojarnos de nuestro yo individual, ya sea por medio de la sumisión a nuevas formas de autoridad o por una forma de conformismo compulsivo con respecto a las normas sociales imperantes" (Fromm, 1995: 140). Este acto de sumisión y renuncia no soluciona el problema de fondo, es decir, la no realización del ser que llevamos dentro, más bien lo pospone o lo agrava: "Mitiga una insoportable angustia y hace posible la vida al evitar el desencadenamiento del pánico en el individuo; sin embargo, no soluciona el problema subyacente y exige en pago la adopción de un tipo de vida que, a menudo, se reduce únicamente a actividades de carácter automático o compulsivo" (Fromm, 1995: 145).

Una organización puede actuar como entidad social o comunitaria en la que se diluye la identidad del individuo que queda subordinado de forma casi inconsciente y en total limitación de su propia personalidad. A esto lleva, en ocasiones, el puro desconocimiento, la desidia, la falta de cuestionamiento o interés $y$, sobre todo, el miedo. "A veces, el miedo lleva a borrarse, a no ser nadie, a refugiarse en el rebaño meramente presente, con renuncia a la biografía personal" (Marías, 1996: 62).

Qué difícil, aunque no imposible, encontrar personas que busquen activamente su desarrollo y organizaciones capaces de respetarlo e incluso potenciarlo. "Tener fe requiere coraje, la capacidad de correr un riesgo, la disposición a aceptar incluso el dolor y la desilusión. Quien insiste en la seguridad y la tranquilidad como condiciones primarias de la vida no puede tener fe; quien se encierra en un sistema de defensa, donde la distancia y la posesión constituyen los medios que dan seguridad, se convierte en un prisionero" (Fromm, 1997: 122). Por desgracia, alguna organización conocemos que parece una fortaleza, en la que sus empleados actúan como guerreros dispuestos a defender sus posiciones y defenderse de quienes las quieren desafiar, sus propios compañeros.

$\dot{¿}^{R i e s g o ? ~ E v i d e n t e m e n t e ~ q u e ~ t o d a ~ a c c i o ́ n ~ c o n l l e v a ~ u n ~ r i e s g o, ~ a l g u n a s ~ m a ́ s ~ q u e ~ o t r a s . ~ P e r o ~}$ también la inacción supone un riesgo, en ocasiones mayor: el de renunciar a una realidad potencialmente mejor. En la vida de un directivo, especialmente si pretende liderar, el riesgo es un com- 
ponente más que hay que saber manejar con eficacia y naturalidad. "Los líderes al límite necesitan, claramente, moverse a gusto por la incomodidad del riesgo. Hay que evitar los riesgos innecesarios, pero hay momentos para movimientos atrevidos. Es preciso comprender los riesgos que se afrontan y evaluarlos minuciosamente. Entonces, hay que sopesar el riesgo y la ganancia, y tener el espíritu de afrontar esos riesgos calculados que merece la pena asumir" (Perkins, 2003:142).

\section{Actúa, ponte en marcha, persevera, pero con eficacia}

En las organizaciones no siempre vemos una correcta identificación, asignación y disposición de personas en función de sus particulares competencias y aspiraciones. El ejercicio de nuestras facultades en ámbitos de actuación sobre los que podemos tener cierta influencia positiva, facilita, en mayor medida, la realización de las metas deseadas. Bandura (1997) utiliza el término efficacy belief (la creencia en la propia eficacia) para referirse al convencimiento de que uno puede realmente provocar determinadas mejoras con sus acciones. Esta convicción actúa a modo de incentivo y potencia las propias capacidades para organizar y llevar a cabo cursos de acción exigidos para la consecución de los objetivos.

Si la gente cree que no tiene suficiente poder para conseguir determinados resultados, ni siquiera tomará las acciones necesarias para intentar que dichos resultados sucedan. Nuestro convencimiento a la hora de hacer algo y la confianza que podamos tener en nosotros mismos son claves al emprender cualquier acción. Por otro lado, si bien es cierto que es mucho lo que depende de la personalidad particular de cada individuo, la organización en la que ese individuo trabaja puede actuar como factor propulsor o ralentizador de este proceso. El término empowerment (apoderamiento) refleja muy bien ese esfuerzo de muchas organizaciones en la actualidad por dar más protagonismo, capacidad de influencia, visibilidad y, en definitiva, poder a sus empleados. ¿QQuién gana con ello? La respuesta es fácil, todo el mundo gana: clientes, empleados, empresa, sociedad en general.

Para poder actuar con eficacia, creer que uno es eficaz es importante, digamos que es condición necesaria pero, sin duda, no suficiente. Parte del secreto de las personas eficaces consiste en que se centran en actividades sobre las que pueden ejercer un control efectivo. Al hacerlo así, consolidan su personalidad y confianza en ellos mismos y afrontan positivamente cualquier reto. Se buscan y obtienen experiencias agradables y reconfortantes, lo cual no significa fáciles o sencillas, y desde esa base se dan un voto de confianza para desafíos futuros. Este es un mecanismo absolutamente seguro de reafirmación y motivación que, además, depende esencialmente de nosotros.

Muchas de nuestras actuaciones son diseñadas y estructuradas mentalmente, a modo de planes, guías, hojas de ruta; escenarios de anticipación o futuros que nuestra mente visualiza como si fueran presentes. Esta anticipación juega un papel fundamental, tanto en la fijación de objetivos como en la motivación para conseguirlos: "Estar motivado significa tener una representación anticipada de la meta, lo cual arrastra a la acción. De ahí emerge buena parte del proyecto personal que cada uno debemos tener" (Rojas, 1994: 22). El hombre maduro se fija objetivos concretos, bien definidos y estimulantes, y pone todo su empeño en alcanzarlos. 
Y si hablamos de empeño, necesariamente hemos de referirnos a la voluntad, que es el complemento perfecto de una sabia toma de decisiones y una fuerte motivación. Injustamente menospreciada, la voluntad se traduce en la capacidad para hacer las cosas que nos hemos propuesto, anticipando las consecuencias y, sobre todo, asumiendo los esfuerzos. Ello exige, a veces, una importante entereza y disposición de ánimo para saber renunciar a lo que nos resulta tentador, cediendo recompensas presentes a cambio de otras futuras que estimamos más atractivas. Con razón se dice que, a menudo, el hombre voluntarioso llega más lejos que el inteligente.

La imagen ideal que tenemos de nosotros mismos puede llegar a ser el principal juez de nuestros actos, juzgándolos en función de su adecuación mayor o menor a ella. En la medida en que somos capaces de adquirir un grado de eficacia personal mayor, la imagen que vamos desarrollando de nosotros mismos va coincidiendo progresivamente con ese ideal que dirige nuestra conducta. Este proceso se manifiesta en tres aspectos fundamentales: "Las sanciones externas son sustituidas por las internas; experiencias de prohibición, temor y deber compulsivo son sustituidas por experiencias de preferencia, respeto de sí y debería ser; y hábitos específicos de obediencia son sustituidos por una conducción de sí genérica" (Allport, 1978: 95).

Al hacer lo que creemos que debemos hacer, para lo que creemos estar mejor dispuestos, en todos los sentidos, nos hacemos un gran favor, nos ganamos nuestro propio respeto y admiración y, seguramente, el de los demás. "Si a lo largo de la vida nos vemos obligados a elegir entre las diversas posibilidades que creamos, y estas sucesivas elecciones nos llevan a ir apropiándonos de algunas características que van pasando a formar parte de nuestro carácter, si somos inteligentes, iremos eligiendo aquellas que aumenten nuestras posibilidades de autoposesión, y no las que vayan produciendo una alienación, una enajenación: no las que nos conviertan en otro, sino las que cada vez nos hacen ser más nosotros mismos. Cuantas opciones alejan a alguien de su capacidad de poseerse están comprometiendo su ser persona" (Cortina, 1996:100).

\section{Servicio: contribución al desarrollo de los demás}

Resulta muy limitado hablar de desarrollo si solo lo hacemos desde una perspectiva individual. Lo apasionante de un proceso de desarrollo personal es descubrir cómo mientras tú creces haces crecer a los de alrededor y cómo el crecimiento de ellos, a su vez, te hace crecer a ti. Poder, estatus, posición, actúan a menudo como trampas en las que, paradójicamente, cuanto más nos enaltecemos menos crecemos. Uno se da cuenta de que las actitudes vanidosas y egoístas acaban siendo contraproducentes para uno mismo. "La vanidad es extremadamente peligrosa cuando sobrepasa cierto grado. Prescindiendo que obliga al hombre a toda clase de esfuerzos y trabajos inútiles, más aparentes que efectivos, haciéndole pensar más en sí mismo y a lo sumo en el juicio que de los demás merezca, acaba por hacerle perder fácilmente el contacto con la realidad. Pasa por la vida sin comprender las relaciones humanas y olvidando lo que aquella le exige y la misión que, como humano, habría de cumplir. La vanidad es capaz, más que ningún otro defecto, de frenar el libre desenvolvimiento del hombre, pues le hace siempre pensar en si lo que hace habrá de captarse con consideración y admiración" (Adler, 1947:158). 
"Muy distinta es la cuestión cuando el valor del individuo se justifica sirviendo a otros. Su valor es entonces natural e indiscutible y se puede permanecer tranquilo contra todo evento, porque no todo se basa en la vanidad. El papel del vanidoso es siempre el de uno que espera y acepta. Si se le compara con aquel tipo que con un desarrolladísimo sentimiento de comunidad, va siempre preguntando tácitamente: ¿qué puedo dar?, saltará inmediatamente a la vista la enorme diferencia de valor de uno y otro. En efecto, el verdadero valor sólo procede del grado de utilidad para otros" (Adler, 1947: 170).

Rosamund Stone Zander lo denomina contribución: "A diferencia del éxito y del fracaso, la contribución no tiene otra cara. No llegamos a ella por comparación. De repente descubre que la temida pregunta -jes suficiente? - o la todavía más temida - $\dot{2}$ me quieren por lo que soy o por lo que hago?- podrían ser remplazadas por la maravillosa pregunta-¿̇cómo contribuiré hoy?-" (Zander, 2000: 57).

¿Cuál es el fundamento, si no, de todo esfuerzo por liderar? ¿ Cuál es el fin último de la pelea que supone conducirse uno mismo y conducir a los demás hacia la consecución de determinadas metas? ¿̇Por qué aguantar presiones, disgustos, situaciones al límite? ¿̇Por qué, en definitiva, luchar por cambiar las cosas? Ronald A. Heifetz considera, simple y llanamente, que la única forma de poder contestar estas preguntas es descubriendo lo que da sentido a la vida, la de cada uno. (Heifetz, 2002: 207).

Todo este esquema, considerando la responsabilidad de aquellos de los que dependen otras personas, nos lleva a propugnar una forma de autoridad diferente a la que se ve y se sufre con frecuencia en las organizaciones. Una autoridad basada en la aceptación consciente y racional del líder por los seguidores, lo que Fromm llama autoridad racional: "La autoridad racional tiene su fuente en la competencia. La persona cuya autoridad es respetada ejerce competentemente su función en la tarea que le confían aquellos que se la confieren. No necesita intimidarlos ni espolear su admiración por medio de cualidades mágicas. En tanto que ayuda competentemente en lugar de explotarlos, su autoridad se basa en fundamentos racionales y no requiere terrores irracionales. La autoridad racional no sólo permite sino que requiere constantes escrutinios y críticas por parte de los individuos a ella sujetos; es siempre de carácter temporal, y la aceptación depende de su funcionamiento." (Fromm, 1997: 21).

La verdadera talla de un líder no viene dada por la intensidad y eficacia con las que domina a sus liderados, sino por la medida en que consigue que se fortalezcan y desarrollen bajo la influencia de su liderazgo. De ahí deriva John Gardner la idea de un liderazgo prescindible, temporal, transitorio, en el que no sólo es posible sino recomendable preparar el terreno para la sucesión: "Si los líderes permiten a los seguidores desarrollar su propia iniciativa, crean algo que acaso sobreviva a su propia desaparición. Algunos individuos que tienen asombrosos poderes de liderazgo personal crean dependencia en quienes están por debajo de ellos y dejan una organización más frágil, poblada por gente debilitada. Los líderes que fortalecen a su gente crean un legado que durará largo tiempo" (Gardner, 1991: 55). 
El reto no es fácil, exige renunciar a uno mismo, al protagonismo propio de la estrella invitada que ha de brillar más que ninguna. Exige admitir que podemos estar equivocados o que, simplemente, las cosas se pueden ver desde otra perspectiva diferente a la nuestra. Parte del crecimiento personal consiste en permitir y potenciar el crecimiento de los demás, el suyo, no el nuestro ni el suyo como el nuestro. Rodearnos de gente diferente a nosotros nos complementa y enriquece, ensancha nuestras miras. "Estoy internamente complacido cuando permito que otra persona sea como es y diferente de mí. A menudo pienso que es amenazador. En cierto sentido lo considero como una prueba de liderazgo y de paternidad. ¿Puedo permitir libremente que este empleado o mi cliente, mi hijo, mi hija sean personas independientes de mí, con ideas, propósitos y valores que pueden no ser iguales a los míos?" (Rogers, 1982: 174). ¿ Hasta qué punto permitimos en nuestras organizaciones o equipos de trabajo que lo diverso, lo diferente, lo que no es como nosotros, esté presente y tenga su protagonismo?

Pero, puestos a desarrollar, żqué desarrollamos de quién, cuándo y de qué modo? Cada individuo tiene sus propias necesidades de desarrollo y no es fácil detectarlas ni compaginarlas con las de los demás, ni con los objetivos de la organización. Además, muchas de estas necesidades, sobre todo las más complejas, están ocultas, no se manifiestan fácilmente. Un buen líder, sin embargo, es capaz de sacarlas a la luz: "Los más grandes poetas, novelistas y dramaturgos siempre han encontrado esas fuentes subterráneas. Siempre han dado expresión a lo inexpresado, siempre han logrado comunicarse con los escondidos elementos que residen en las almas de sus lectores. Los líderes más hábiles comparten el don de comprender y seguir con una comunicación similar" (Gardner, 1991: 230).

Hay un doble esfuerzo que realizar: por un lado, llegar al otro, a su ser peculiar y más íntimo; por otro, antes y como requisito previo, despojarse de uno mismo, distanciarse y, simplemente, observar. "Creo que cuando el asesor puede atrapar la vivencia que fluye segundo a segundo en el mundo interior del cliente tal como éste la ve y la siente, sin dejar de mantener la separación de su propia identidad en este proceso empático, es probable que sobrevenga el cambio" (Rogers, 1980: 96). Se intenta entender al otro, pero sin dejar de ser uno. Al final y en definitiva, acabas comprendiendo que es más y, sobre todo, más importante lo que nos une que lo que nos separa de los demás.

Observar sin juzgar, comprobar sin presuponer, mirar para ver y no para ratificar; realmente, la tarea es complicada, tenemos mucho que desaprender. "El método más eficiente para percibir la naturaleza intrínseca del mundo, consiste en ser más receptivo que activo, determinado hasta donde sea posible por la estructura intrínseca de lo percibido y lo menos posible por la naturaleza del perceptor. [...] ¿ Contemplas el mundo real y concreto, o estamos contemplando nuestro propio sistema de rúbricas, motivos, esperanzas y abstracciones que hemos proyectado sobre el mundo real? O, por decirlo taxativamente, ¿̇vemos o estamos ciegos?" (Maslow, 1968: 69).

Todos estos principios y, seguramente, algunos más, expuestos de una u otra manera, con un mayor o menor énfasis, van orientados hacia una misma línea de actuación, coherente con un mismo mensaje de fondo: pocas cosas debe haber más importantes para un ser humano que llevar a 
cabo su proyecto vital como persona. Nada ni nadie (organizaciones, rígidas estructuras, jerarquías, jefes,...), por fuerte, intensa y duradera que sea la presión que ejerza, puede distraer de este destino a su protagonista. En este recorrido no estamos solos, nos acompañan y acompañamos, pero hemos de ser nosotros los que tomemos la iniciativa. Una vez comenzado el camino, encontraremos otros caminantes en situación parecida a la nuestra.

Por eso, más allá de las iniciativas de tal o cual organización, con liderazgo "de primera o de segunda calidad", más allá de las buenas o malas intenciones de directivos, cercanos a los postulados de la Teoría $X$ o de la Teoría $Y$, coherentes o incoherentes en su afán por liderar y contribuir al desarrollo de otros, debemos ser nosotros, primero nosotros, los que actuemos, siempre. El desarrollo personal es una tarea que compete, por encima de todo, a cada interesado.

Si los datos que ofrecen los dos estudios mencionados en este artículo reflejan algo parecido a lo que sucede en la realidad empresarial de hoy o no, es una cuestión importante pero secundaria frente a la necesaria asunción de responsabilidad personal de cada uno respecto a su desarrollo. En la medida en que todos y cada uno de nosotros lo creamos firmemente, contribuiremos, desde nuestros respectivos puestos y responsabilidades, a que el desarrollo personal tenga vigencia en nuestras organizaciones, en nuestras vidas. Para ello, necesitamos criterios, valores, principios rectores que inspiren nuestras actuaciones. Sabiduría al interpretarlos, inteligencia al aplicarlos y constancia y coherencia al vivirlos, harán el resto.

Unamuno, en pocas palabras, resume la esencia de este planteamiento orientado al desarrollo personal, de uno mismo y de los demás, con los demás, dentro o fuera de una organización, en cualquier organización, gracias a ella o a pesar de ella. El desarrollo personal, ante todo y sobre todo, responsabiliza al ser humano, a cada uno de nosotros, respecto a nosotros mismos y a los demás: "Avanza, pues, en las honduras de tu espíritu, y descubrirás cada día nuevos horizontes, tierras vírgenes, ríos de inmaculada pureza, cielos antes no vistos, estrellas nuevas y nuevas constelaciones. ... En vez de decir, pues, jadelante!, o jarriba!, di: jadentro! Reconcéntrate para irradiar; deja llenarte para que rebases luego, conservando el manantial. Recógete en ti mismo para mejor darte a los demás todo entero e indiviso. -Doy cuanto tengo-, dice el generoso; -Doy cuanto valgo-, dice el abnegado; -Doy cuanto soy-, dice el héroe; -Me doy a mí mismo-, dice el santo; y di tú con él, y al darte: -Doy conmigo el universo entero-. Para ello tienes que hacerte universo, buscándolo dentro de ti. ¡Adentro!" (Unamuno, 1977: 183-189).

\title{
REFERENCIAS BIBLIOGRÁFICAS
}

\author{
- Adler, A. (1947): Conocimiento del hombre, Madrid: Espasa-Calpe. \\ - Allport, G. W. (1978): Desarrollo y cambio, Buenos Aires: Paidós. \\ n Álvarez de Mon, S. (2000): El mito del líder, Madrid: Pricewaterhouse Coopers. \\ - Bandura, A. (1997): Self-efficacy. The exercise of control, Nueva York: Freeman and Company.
}


- Camps, V. (1996): La desmoralización de la vida pública; Ética pública y moral social, Madrid: Noesis.

- Collins, J. (2001): Good to great, Londres: Random House Business Books.

- Cortina, A. (1996): El quehacer ético. Guía para la educación moral, Madrid: Santillana.

- Fichte, J. G. (1963): El destino del hombre, Ávila: Aguilar.

- Frankl, V. E. (1979): El hombre en busca de sentido, Barcelona: Herder.

- Frommm, E. (1997): El arte de amar, Barcelona: Paidós.

- Fromm, E. (1995): El miedo a la libertad, Barcelona: Paidós.

- Fromm, E. (1957): Ética y psicoanálisis, México: Fondo de Cultura Económica.

= Gardner, J. W. (1991): El liderazgo, Buenos Aires: Grupo Editor Latinoamericano, Colección Estudios Políticos y Sociales.

- Heifetz, R. A.; Linsky, M. (2002): Leadership on the line, Boston: Harvard Business School Publishing.

- Lavelle, L. (1951): Tratado de los valores, París: P.U.F.

- McGregor, D. (1985): The human side of enterprise, Nueva York: McGraw Hill.

- Marías, J. (1996): Persona, Madrid: Alianza Editorial.

- Maslow, A. (1968): El hombre autorrealizado, Barcelona: Kairós y Litton Educational Publishing Inc.

- Méndez García, J. Mํ. (1988): Teoría del valor, Madrid: Estudios de Axiología.

- Olmos, E. (1994): La plenitud humana, Madrid: Artes Gráficas Hono S.L.

- Ortega y Gasset, J. (1947): Obras completas, vol. VI, Madrid: Revista de Occidente.

- O'Toole, J. (1999): Leadership A to Z, San Francisco: Jossey-Bass Inc. Publishers.

- Perkins, D. (2003): Lecciones de liderazgo, Madrid: Desnivel ediciones.

- Rogers, C. (1982): Libertad y creatividad en la educación, Barcelona: Paidós.

- Rogers, C.; Stevens, B. y colaboradores (1980): Persona a persona, Buenos Aires: Amorrortu editores.

- Rojas, E. (1994): La conquista de la voluntad, Madrid: Temas de Hoy.

- Sartre, J. P. (1960): Existentialism and Human Emotions, New York: Philosophical Library Inc.

- Savater, F. (1991): Ética para Amador, Barcelona: Ariel.

- Unamuno, M. (1977): Adentro, Obras selectas, Madrid: Biblioteca Nueva.

- Vallés, C. G. (1987): Ligero de equipaje, Santander: Sal Terrae.

- Zander, R. S. (2000): The art of possibility, Nueva York: Penguin Books Ltd. 